\title{
Pricing European multi-asset options using a space-time adaptive FD-method
}

\author{
Jonas Persson · Lina von Sydow
}

Published online: 23 August 2007

(C) Springer-Verlag 2007

Erratum to: Comput Visual Sci (2007)

DOI: 10.1007/s00791-007-0072-y

The original online version of this article unfortunately contains a mistake. The name of the second author is Lina von Sydow.

The online version of the original article can be found under doi:10.1007/s00791-007-0072-y.

J. Persson $(\varangle) \cdot$ L. von Sydow

Department of Information Technology, Scientific Computing,

Uppsala University, Box 337, 75105 Uppsala, Sweden

e-mail: jonas.r.persson@gmail.com

L. von Sydow

e-mail: lina@it.uu.se 